\title{
How to Sell a Friend: Disinterest as Relational Work in Direct Sales
}

\section{Curtis Child}

\author{
Brigham Young University
}

Abstract: Economic sociologists agree that monetary transactions are not necessarily antithetical to meaningful social relationships. However, they also accept that creating "good matches" between the two requires hard work. In this article, I contribute to the relational program in economic sociology by examining a common but understudied type of work in which one party to a relationship stands to benefit from it financially. I identify in these highly commercialized contexts a particular style of relational work anticipated, but not fully developed, in Pierre Bourdieu's writings: disinterest. I argue that the disinterested style is manifest by economically implicated individuals who downplay their objectively apparent economic interests in order to preserve or encourage good feelings about a relationship that is meaningful to them. Drawing upon data from the direct selling industry, I show how distributors use disinterest to navigate their work.

Keywords: economic sociology; social theory; disinterest; Bourdieu; morals and markets; multilevel marketing

Citation: Child, Curtis. 2021. "How to Sell a Friend: Disinterest as Relational Work in Direct Sales." Sociological Science 8: 1-25.

Received: September 18, 2020 Accepted: October 20, 2020

Published: January 6, 2021

Editor(s): Jesper Sørensen, Gabriel Rossman

DOI: $10.15195 / \mathrm{v} 8 . \mathrm{a} 1$

Copyright: (C) 2021 The Author(s). This open-access article has been published under a Creative Commons Attribution License, which allows unrestricted use, distribution and reproduction, in any form, as long as the original author and source have been credited. (0)(1)
U ${ }^{\text {OW }}$ people make their economic interests congruous with meaningful social 1 relationships is a central problem in economic sociology (Bandelj 2020; Zelizer 2012). Though ever evolving, the technologies of exchange are rather straightforward; the sociology of exchange, however, is not. That is, although we might easily understand the mechanics of how money gets transferred in relationships, we do not yet have a full sociological account of how people navigate those transactions. This is especially true for transactions that take place among known others, where participants must work hard to affirm a relationship's meaning while engaging also in unmistakable economic activity (Zelizer 2000).

Recognizing that social relationships and economic activities go hand in hand, economic sociologists have been eager to study the work that makes socially and economically "connected lives" a reality (Zelizer 2005). Past research affirms that connected lives are indeed possible, but scholars understand good matches between economic transactions and social relations as an accomplishment rather than a given (Zelizer 2006). An important goal of the relational school in economic sociology has been to make sense of relational work in economic transactions (Bandelj 2020).

In this article, I contribute to the relational program in economic sociology by examining a common but understudied type of social relationship in which one party to the relationship (i.e., an acquaintance, friend, or family member) stands to benefit from it financially. I ask, how do the protagonists of these economic intrusions negotiate their financial interests with their relational ones? Answering this question provides insight into how relationships operate in highly commercialized contexts. In contemporary market societies, everything is for sale (Kuttner 
1999) - including cherished things that, some argue, should be guarded from the market's reach: our bodies and their parts (Anteby 2010; Healy 2006), our health (Reich 2014), our movements (Schechner, Glazer, and Haggin 2019), our identities (Sullivan 2018), our deaths (Quinn 2009), and, to the point of this article, our relationships. Although normative questions, such as what should be for sale (Sandel 2012), are no doubt worth asking, it is also valuable to consider how people manage their attempts at such sales given social norms that prohibit using friends and family for instrumental ends.

I address these issues by investigating the direct selling industry, where products are sold not through online or physical storehouses but through person-to-person contact (Federal Trade Commission 2018). Direct sales, a $\$ 35$ billion dollar industry, involves more than 6 million direct sellers and nearly 37 million customers (Direct Selling Association 2019). I focus on one segment of the industry, multilevel marketing. In multilevel marketing, relationships with distributors can be complicated in two ways: First, distributors ask acquaintances, friends, and family to purchase products from them. Second, distributors recruit acquaintances, friends, and family members to become members of their selling teams. Both activities-selling and recruiting - benefit the distributor financially and involve financial and, often, social costs to their prospect. ${ }^{1}$

A simple answer to the question of how these distributors negotiate their economic interests with their relational ones is that sellers are so acquisitive they are willing to prioritize money over loved ones. However, I find that this is not the case. Distributors are aware of the prevailing social norms that marshal against using friends and family for bald economic gain. Moreover, many distributors do not identify as salespeople, and most are self-conscious about being pushy (see also Mullaney and Shope 2012). Remarkably, distributors themselves commonly complain about their negative experiences of being sold to by other direct sellers. In light of these findings, I document a disinterested style of selling adopted by distributors.

Borrowing from Bourdieu (1980, 1983, 1984, 1998; see also Grenfell 2012; Sayer 1999; Swartz 2012; Swedberg 2005), I use "disinterest" as a way to make sense of distributors' unique approach to their work, which is variously passive, indirect, and other-oriented. More than an effort to signal distinction (Hahl, Zuckerman, and Kim 2017; Schor et al. 2016), I argue that disinterest is a style characterized by economically implicated individuals who downplay their objectively apparent economic interests in order to preserve or encourage good feelings about a relationship that is meaningful to them. Disinterest, then, becomes a way for economically motivated individuals to navigate an increasingly commercialized world without feeling that they have themselves become fully commercialized people.

\section{Background}

\section{The Problem of Economic Transactions}

Although the conventional wisdom is that economic transactions in meaningful social relationships are fundamentally problematic, the Zelizerian tradition in eco- 
nomic sociology holds that social life marches forward in many instances not despite the presence of economic transactions in social relationships but, importantly, because of them. Zelizer documents in case after case that social relationships do not just tolerate economic intrusions but, rather, that relationships and economic exchange often go hand in hand (Zelizer 1989; Zelizer 1996; Zelizer 2005; Zelizer 2006). Far from Marx's worry that money would, in Zelizer's (1989) words, "debase personal relations into calculative instrumental ties" (P. 345), Zelizer argues that economic exchanges mark and differentiate meaningful relations in consequential ways (Zelizer 2000). For example, we use money not only to purchase gifts for our loved ones, thus affirming our devotion, but we do so in such a way that differentiates our loved ones from others with whom we are less enamored (Zelizer 2006). Money and economic exchange thereby become means of facilitating relationships as much as they are an avenue for corrupting them.

Although Zelizer offers a highly plausible counternarrative to the argument that social relations and monetary exchanges necessarily corrupt each other and should therefore be kept separate (Zelizer 2000), it is still true that money can corrupt relationships (Zelizer 2006). Furthermore, the fear of relational corruption remains a common cultural motif (Zelizer 1978). Societies tend to divide their worlds into things sacred and things profane, a fundamental distinction that shapes much of what their members value or resist (Durkheim 1915; Lukes 1985). Unless sacralized (Belk, Wallendorf, and Sherry 1989; Belk and Wallendorf 1990), money and economic transactions reside in the world of the latter, which helps explain popular opposition to mixing them with relationships (even if, in practice, people mix them all the time).

These complexities-evidence suggesting that monetary transactions do not necessarily destroy relationships set against the recognition that monetary transactions could hurt relationships and that the fear of them doing so prevails in contemporary society - suggest that there is ample room to understand how economic transactions and social relations work together. Zelizer (2006) says as much when she observes that "good" matches-meaning "viable" matches between economic transactions and intimate relations that "get the economic work of the relationship done and sustain the relationship" (P. 307)—are not a given. The specter of "bad" outcomes is always lurking in the shadows, so people work to make them good. The nature of this work is the subject of this article.

\section{Disinterest in Commercialized Relationships}

Making sense of the work that goes into sustaining relationships is important if we are to understand how relationships survive, if at all, in an increasingly commercialized world. To that end, I build on the work of Bourdieu (1980, 1983, 1984, 1998; see also Grenfell 2012; Sayer 1999; Swartz 2012; Swedberg 2005) by documenting a style of relational work whose purpose is to ease the potentially corrupting consequences of mixing social relations and money. I find that network marketing distributors-notable for their explicit use of relationships for economic purposes - manifest a pronounced disinterest in the fiscal aspect of their direct selling relationships, which I argue is an effort to protect the relationship from ruin. 
Disinterest, as I use it here, occurs when a member of a commercialized relationship downplays their objective economic interests in order to preserve or encourage good feelings about the relationship. I define commercialized relationships as social relationships that have an explicit economic quality to them-that is, wherein at least one party to the relationship stands to benefit personally from economically profitable transactions with the other party. The social relationships I have in mind are those between known others-acquaintances, friends, and family-not the impersonal, fleeting relationships that occur between some market participants. Examples include an insurance-agent sister who wants her siblings to transfer their policies to her firm, an entrepreneur son who asks parents and family members to support his venture, and a realtor friend who solicits referrals from their peer network. Of course, the economic and the social often complement each other (Zelizer 1989; Zelizer 1996; Zelizer 2005; Zelizer 2006), but shows of economic disinterest may help cloak the former (the crude economic transaction) in the hopes of creating a sense that the latter (the meaningful social connection) is unsullied by market pressures. In the very act of pursuing an economic transaction, disinterest communicates that the transaction is not economically motivated, which thus reaffirms the relationship's perceived sanctity.

Commercialized relationships can be burdensome to participants. When a relationship becomes commercialized-when Afton asks Remy to purchase a product whose sale could enrich Afton at a cost to Remy-then the motives of the selling party are an open question: is Afton sincere in her friendship, or is she reaching out only because she is interested in making a sale? It is not the money itself that potentially spoils the relationship (see Zelizer 2000) as much as it is the interest in financial gain that raises suspicions about the relationship's intrinsic orientation-the degree to which the relationship is important for the sake of the relationship and not because of the monetary value it can bring (Grayson 2007). Economic transactions between known others call forth the specter of instrumentality, which undermines the authentic motives for intimacy and other-orientedness (Hahl and Zuckerman 2014; Hahl et al. 2017) — the stuff on which modern relationships are thought to be built (Mullaney and Shope 2012; Silver 1989; Silver 1990).

Aware of these complexities, participants to commercialized relationships might see disinterest as a way to deal with the problems that such relationships introduce. By attending to sacred social relations and showing disinterest in profane economic transactions (even if in reality the two are inseparable), participants to commercialized relationships might believe they can obfuscate the ulterior, morally problematic part of the transaction (Schilke and Rossman 2018). By hiding it from view, they could persuade others-and perhaps even themselves-that their actions are acceptable and possibly even virtuous.

\section{How Disinterest Works}

Understanding how Bourdieu's notion of disinterest might operate in the context of commercialized relationships requires first revisiting his ideas about interest (see Bourdieu and Wacquant 1992; Bourdieu 1998; Grenfell 2012; Swartz 2012; Swedberg 2005). For Bourdieu, all action is interested action in the sense that those actions 
are oriented to achieve some advantage, which could be material or symbolic. People are strategic in their efforts to achieve their goals, meaning that their actions align with the steps necessary to realize their desired outcomes. This is not to say, however, that they are entirely conscious of their strategizing (Bourdieu and Wacquant 1992; Bourdieu 1998; Johnson 1993; Sayer 1999). Embedded as they are in a particular social location, and imbued with the resulting habitus, they may be simply acting in a way that, to them, seems obvious and normal (Bourdieu 1990).

Notwithstanding the fact that all action is interested action, according to Bourdieu, in certain fields, such as art and religion, showing interest is unacceptable (Bourdieu 1998). Instead, people enact disinterest (Bourdieu 1980, 1983, 1984, 1998; Swartz 2012; Swedberg 2005). That is, they demonstrate symbolically-through language, actions, and other signifiers-that they are motived by an elevated (i.e., nonpecuniary) cause. Artists, for instance, are supposed to make art for art's sake, not simply to become wealthy (Bourdieu 1983). Because success in the field requires being disinterested in money, revealing their "mundane" interests in economic survival could be detrimental to artists' status, leaving outsiders to regard them as insincere and inauthentic, which in turn would discredit them and spoil the artistic enterprise altogether. If they succeed at showing disinterest, however, others will see honorable motives instead of base ones, and the artists will thereby preserve their legitimacy. Under such circumstances, members of the field all get what they want: artists get to pursue their interests, albeit under the banner of disinterest, and their audiences get to believe that artists are doing art for the sake of art and art alone. As with interest, displays of disinterest might not be disingenuous, as members of the particular field are responding less to their internal cost-benefit calculations and more to the expectations of the social context (Bourdieu and Wacquant 1992; Grenfell 2012).

Disinterest works, at least in part, by shoring up perceptions of authenticity. It does so by implying to audiences that actors have no ulterior motives for engaging in the audience-approved act (Hahl and Zuckerman 2014). In modern society, where authenticity is in high demand (Grazian 2005; Hahl 2016), disinterest becomes a way to acquire it —or at least to protect it. Evidence suggests that actors themselves (i.e., not audiences only) understand the importance of authenticity and therefore pursue disinterest out of a desire to increase it. Hahl et al. (2017) show experimentally that authenticity-insecure subjects preferred low-brow to high-brow culture because low-brow culture was produced without regard for external reward-that is, in a disinterested way. By association, elites hope that the "aura of authenticity" (P. 829) will rub off on them. Like Bourdieu's artists, they hope to "prove [their] claim to authenticity by [their] disinterestedness" (1983:321).

\section{Forms of Disinterest}

Although Bourdieu mentions disinterest frequently in his writings (see Bourdieu 1980, 1983, 1984, 1998; see also Grenfell 2012; Sayer 1999; Swartz 2012; Swedberg 2005), he was unfortunately not very explicit about how it is manifest empirically in interpersonal relationships (Schor et al. 2016), and he provided only scattered clues that would help us know how to identify it. His theory is thus underdeveloped, 
or at least not fully articulated. He provides the germ of an idea, but it lacks the specificity that would be helpful in exporting the concept to different locales. This is a problem for us if, as he did, we suspect that disinterest is a useful concept for apprehending our social worlds.

Beyond contributing to relational economic sociology by identifying a type of relational work, one aim of this article, therefore, is to unearth and expand on Bourdieu's notion of disinterest. I do so by, first, piecing together from his writings the manner in which he thought disinterest is used. I suggest he identified two: disinterest through disavowal and disinterest through transfiguration. Second, I use my data to identify two additional forms of disinterest, what I call disinterest through displacement and disinterest through transposition. I summarize Bourdieu's perspective on disavowal and transfiguration here before touching lightly on displacement and transposition, which I develop more fully in the Results section.

We find in Bourdieu's accounts hints of people showing disinterest through disavowal when they state plainly or implicitly that they are not interested economically. Bourdieu thus writes about people "disavowing" the economy (1980:261), "refusing" the commercial (1980:261), "renouncing economic profit" (1980:268), "denunciating mercenary compromises" (1980:265), and making "statutory professions of disinterestedness" (1983:321). Sometimes disavowal is less explicit, such as when one plays down or suggests indifference to economic interest without denying it outright (1980:288). For instance, Bourdieu writes about a religious leader laughing dismissively when pilgrims are referred to as the "clientele" (1998:118). The religious leader does not disavow the economy outright but still denies the economy by showing indifference to it.

A second way of showing disinterest is through transfiguration. For Bourdieu, this means changing the profane, economic thing into something noneconomic, even sacred-that is, turning "raw material into a beautiful object" (1998:114). This often happens through euphemism, or-according with the "taboo of making things explicit" (1998:96)—obscuring one's interest by being imprecise and indeterminate (Bourdieu 1980:264; Bourdieu 1984:228; Bourdieu 1990:110-14, 126; 1998). Religious work again provides an example. Bourdieu observes that it "includes a considerable expenditure of energy aimed at converting activity with an economic dimension into a sacred task" (Bourdieu 1998:119). If a minister's solicitation for tithes was described plainly as an effort to pay off her mortgage, then she could be discredited as being too caught up with the things of this world. Far better to transfigure the transaction, discussing it euphemistically in terms of a sacred obligation to support God's work on Earth. Doing so would manifest her apparent disinterest in the economic world and at the same time emphasize her commitment to the spiritual one.

To disavowal and euphemism I add displacement and transposition. Displacement is replacing one possible narrative about the commercial intrusion to the relationship - that is, that it is an effort to exploit friends and family for personal gain-with a disinterested, noneconomic narrative. A distributor, for example, might talk up the noneconomic aspects of her direct selling relationships (the sociality, fun, and community) as a way of crowding out the economic narrative and emphasizing that the social is what really matters. Transposition, by contrast, is 
transferring the blame of the economic intrusion to another member of the relationship. In direct selling, for instance, a distributor might take a passive approach to selling, waiting for a potential buyer to first indicate their interest. Economic interest still exists in the relationship, but the distributor is not culpable for its presence.

\section{Situating the Argument}

This study advances scholarship in two ways. First, I use these insights to shed light on the kinds of effort people exert to make their economic interests congruous with their social relationships. In so doing, I build on Zelizer's $(2005 ; 2012)$ relational economic sociology by suggesting a largely overlooked form of relational work. Specifically, I argue that Bourdieu's notion of disinterest offers fresh perspective into the problem of commercialized relationships, above and beyond what other accounts provide. Second, I outline Bourdieu's theory of disinterest, offering clarity on a subject that runs throughout his writings but not always in a way that is easy to understand. I uncover in his writings two types of disinterest (disavowal and transfiguration) and, based on the results reported here, add two others (displacement and transposition). I thus clarify and build on Bourdieu by providing insight into how disinterest is identifiable in interpersonal relationships, something that is often hidden in his accounts (Schor et al. 2016).

\section{Data and Method}

Multilevel marketing is ideally suited for studying commercialized relationships, and the western state in the United States from which the sample is drawn is ideal for studying multilevel marketing. During the years of researching and writing, estimates from the Direct Selling Association indicate that this state ranked higher than most or all other states in the nation in terms of per capita involvement in direct selling. Anecdotally, interviewees characterized the region in which the data were collected as a direct selling "Mecca."

For practical reasons, I limited sampling to one of the more populated counties in the state. Within that county, I targeted my efforts to 10 of its cities, which ranged in size from about 10,000 to just over 100,000 residents. All of the cities are part of the same metropolitan statistical area, which has a total population of more than 500,000 . The median income in the county is $\$ 70,000$, with major employment in higher education, health care, and a growing tech industry. Top employers also include multilevel marketing companies, several of whose headquarters are located in the region. Residents are educated, with nearly four-fifths possessing at least some college education. Roughly 80 percent of the county is white non-Hispanic; of the remaining 20 percent, the majority identify as Hispanic.

I sampled direct sellers in the following way. First, to increase the likelihood that distributors would have experience selling to acquaintances, family, and friends, I focused on multilevel marketing companies that sell health, beauty, and fashion products. Based on web and social media searches, a research assistant and I identified five focal companies popular in the area. Essence (all names of organizations 
and people are pseudonyms) specializes in essential oils, sourced throughout the world. It boasts millions of distributors and customers. Motif, a fashion company, sells clothing for women and men. At its peak, annual sales reportedly surpassed $\$ 2$ billion. Started in the early 2000s, Vital promotes its vision of health through body wraps and dietary supplements. Although many of its products focus on weight loss, Vital also sells beauty products, such as antiaging solutions, and energy boosters. Glitz and Splendor, the remaining two companies, both focus on beauty and skin care products. The oldest of all the companies, Glitz sells globally, generating $\$ 1$ billion in revenues in a recent year. Splendor, established in the last decade, reports 1.5 million distributors throughout the world.

After identifying these focal cities and companies, a research assistant and I built a database of distributors through targeted Facebook searches and, when available, online lists of distributors. Once the database was populated, for each company we randomized the list of potential interviewees and started sending invitations-by phone call, text, and Facebook Messenger-to participate in the study. In all, we made attempts to contact 107 distributors during 2018 and 2019 to secure an interview. Of those, we estimate 83 potential interviewees received the invitation, and we interviewed 46 of those 83 (or 55 percent). The remaining distributors agreed to be interviewed but the interview never materialized ( $n=9$, or 11 percent), declined the invitation ( $n=17$, or 20 percent), or saw the request but did not respond to it ( $n=11$, or 13 percent). Of the 46 interviews, two included husband-wife teams, bringing the total number of interviewees to 48 .

With three exceptions, the interviewees were women, nearly all of them married with children. Their average age at the time of the interview was 36 , with a median number of two children at home. The mean years of experience in direct selling was 3.2, with distributors devoting an average of 15 hours per week to direct sales work. Forty percent of interviewees work other jobs as well (e.g., a teacher, credit analyst, hair stylist, machine operator, administrative assistant, etc.).

Interviews took place in a university office, at the interviewee's residence, or at a public location-whichever the interviewee preferred. On average, interviews lasted 85 minutes; all but one were recorded. Most interviews involved the distributor and two researchers (the author of this article and a research assistant). Interviews were semistructured (following Weiss 1994), organized around themes such as the interviewee's ideas about friendship, their history with direct selling, how they find people to sell to, how they conceptualized the social boundaries of their work (e.g., whether they feel uncomfortable selling to anyone), how their work in direct selling affected their relationships positively and negatively, and their experiences with their particular direct selling company (e.g., trainings, conventions, etc.).

Although not a formal part of this report, insights from the interviews with distributors are complemented with insights from scores of interviews with people who have been sold to by distributors (i.e., prospects), as well as 75 hours of observations at in-person and virtual conventions (producing more than 100,000 words of field notes). Among other things, the additional interviews confirm that, indeed, many prospects resent being sold to by acquaintances, friends, and family 
for a variety of reasons. As one put it, distributors are "really just doing it for the money."

We analyzed the data as we collected them. During and after interviews, I (or a research assistant) recorded notes on themes present in the interview. We also kept notes on themes that transcended individual interviews, which we updated and revised throughout the data collection process. Thus, by the time data collection ended, I already had a list of themes relevant to the study question. I used these and other emergent themes to code interview transcripts. I combined and split codes, as necessary, throughout analysis. Codes fell roughly into eight categories, focusing on the interviewee's background, their experience working for the particular company (including their motivations and sense of commitment), how they conceived of social boundaries in their work (e.g., what is appropriate, what is not), what they do not like about other direct sellers, how they perceived themselves, what helped them navigate their work, the positive benefits of selling, and the company's role in the process. Each of these categories had multiple subcategories.

Along with coding, I was aided by memos and analytic matrices. In memos (Corbin and Strauss 2014), I organized my evolving understanding of the data and saved interview excerpts useful for illustrating what I had learned. I used analytic matrices (Miles and Huberman 1994) to gain a bird's-eye view of the data, which helped identify patterns across the entire data set.

During and after coding the data, I further considered how the different themes fit together conceptually and in relation to other published scholarship. I reread the coded excerpts by theme, making further notes about consistencies, subthemes, and disconfirming evidences. The result was an interview data set coded thematically and about three dozen memos of varying length (only some of which are germane to this article). Moving between data, notes, and the literature, my goal was to develop a conceptual frame that represented accurately the raw data. As is typical of qualitative work, I represent those data-which are too voluminous to be presented in their entirety-through the medium of quotations, observations, and interpretations. Each subsection of the Results draws on one or more of the codes, organized by Bourdieu's notion of disinterest, which I found particularly useful for shedding light on the data.

\section{Results}

A sociological account of commercialized relationships, such those in which distributors engage, must first address the extent to which participants are aware of the social norms that they are supposedly violating, as well as the extent to which their motivations are financial. The puzzle of direct selling - how and why sellers are willing to use friends and family for personal gain, and how they traverse that murky territory-is not too puzzling if sellers are in fact naive about how one should treat a friend or family member, or if they are not acting out of economic interest. Popular representations of direct sellers portray them as ignorant at best and rapacious at worst; they are either conned or are themselves cons, willing to turn their friends and families into business opportunities. Regardless, they are unaware of social norms or willing to flout them without remorse. 
In fact, because they are participating in multilevel marketing for pay, rather than as volunteers (such as by throwing fashion or makeup parties simply for fun and not remuneration), it is safe to presume financial interest on their part. As to whether they are aware of the social norms they might be violating, there is evidence to suggest they are. The distributors I interviewed talk about friendship in ways that resonate with broader cultural understandings. Moreover, most of the direct sellers I interviewed do not identify as salespeople, are acutely aware of seller stereotypes, or are themselves antagonized by negative interactions with other direct sellers. Julie insists that she is "not a salesperson," and others confess to feeling shy, introverted, and anxious at the thought of asking people to purchase a product (similar to the distributors in Mullaney and Shope 2012). Distributors are aware of negative distributor stereotypes and have themselves been subjected to other direct sellers' vigorous recruiting efforts, which they often find distasteful. "I'm very anti-MLM [multilevel marketing] in general," Zoe-a distributor-says. "Not the idea of it, but people are always awful."

Many interviewees connect their negative experiences being sold to with their own approach to selling. More than being cognitively aware of direct seller stereotypes, that is, and different than being turned off when subjected to other direct sellers' advances, the distributors I interviewed resist adopting an aggressive approach in their work because they "don't want to be that person," as Jennifer puts it. That person, or that girl, is an economically interested seller who pushes the sell without regard to the needs or capacities of the potential buyer. Distributors care about how others see them and how they see themselves, and being that person interferes with their idealized image of a genuine friend. "I never wanted to be that person," Jill says, for whom "it's like everything you post on social media on your personal page is related to the business." "Because I'm not that person," she explains. "I'm not the person that only is selling or only cares about the money."

Distributors, therefore, are not simply unaware of or indifferent to social norms that dictate against using family and friends for instrumental gain. They talk about friends in ways that would seem familiar to most Americans. For the most part, they do not identify as salespeople. And they often find selling awkward and uncomfortable. They are aware of negative direct seller stereotypes, have had negative experiences of their own with direct sellers, and talk candidly about their efforts to not make their own sales experiences turn out badly.

\section{Disinterest through Disavowal}

It is against the backdrop of not wanting to be that person that distributors manifest a unique style of selling. Instead of being conspicuously interested in turning their friends and family into business opportunities, distributors often adopt an indirect, passive approach to selling. This means that a distributor works to show others, and perhaps to convince herself in the process, that she is not the stereotyped network marketer who willingly sacrifices meaningful relationships in order to earn a dollar. Less an aggressive, robotic salesperson, she is an available, genuine friend. Of course it is nevertheless true that distributors, by virtue of being sellers, 
are interested economically in the exchange, and such is the paradox of network marking.

Disinterested distributors need not sanitize themselves of all financial interest, but they must demonstrate to themselves and others that financial interest is not the driving force behind their participation in what is at its core a potentially lucrative financial transaction. One way of showing disinterest is through disavowal, a style documented by Bourdieu (1980, 1983, 1984, 1998). In disavowal, the distributor denies that she is motivated fundamentally by economic considerations. A direct, explicit kind of disinterest, it takes the form of suggesting that one is not concerned about the economic consequences of one's selling work. At its most strident, it is manifest in proclamations that the financial aspects of direct selling are unimportant.

Distributors do disinterest by showing that they are unattached to the sell. Thus, even if distributors make a pitch to friends or family members, they are sure to downplay its importance. In interviews, distributors repeatedly contend that they are not at all bothered when others turn down their invitations. "Hey, you know, I've got this [product], if you'd like. No pressure," Nicole tells her invitees. "I don't care if I don't sell anything. Just come because I'd like to visit with [you]. [...] You don't have to buy anything. Just come and hang out with me and say 'hi.' " By reminding potential buyers that the focus is on connecting, "then people know that, like, 'I care about you, not the sale.' "'

Other distributors make similar claims of disinterest, only partially represented in statements such as these: "If you don't like it, that's fine" (Elizabeth); "If you don't want it, no big deal" (Autumn); "If she doesn't [buy from me], that's okay" (Shannon); "It wasn't for them, and that's okay" (Cheri); "My feelings wouldn't be hurt from anyone" (Audrey); "If they don't want to support me, it's not a big deal" (Susan); "If she doesn't want to use it, that's fine; I don't care" (Carrie); "I'm not going to take it personally" (Kelly); "If they like it, they like it. If they don't, they're not going to hurt my feelings" (Julie); and, "If they're not interested, who cares?" (Amy). Each statement is a different way of saying, as Emma does, "totally okay." "They know that I'm their friend first."

Some distributors go so far as to buttress their claim to disinterestedness by saying that the financial aspect of the exchange is decidedly not a motivating factor. Carrie provides an example: "I'm not gonna just go sit down by [family and friends] and be like, 'Oh, hey, I'm selling lipstick. You should come try it.' Y'know, I wasn't like that." "I don't need the money," she asserts. Then, further downplaying the importance of financial gain in a form similar to others, she says, dismissively, "If people buy from me, great. But if they don't, that's fine too. I don't care." Cheri says, similarly, "My husband does really well. It's not about the money," which Erica echoes:

I don't care! Like, if you don't like it, I don't want you to buy it, right? If you don't have the money for it, you don't want to spend your money there, I don't care. Like that's not, that's not why I'm doing this. I'm showing you this because I think you'll like it, right? [...] But if they don't, or they don't want to buy it right now or whatever, it's not a big deal to me, you know? [... ] I really wanted people to know that I did 
not start this to make money. [...] I mean, we put money in, so we get money out, you know, but that wasn't my reason.

\section{Disinterest through Transfiguration}

Along with disavowal, Bourdieu (1998) identified transfiguration as a way of showing disinterest. Whereas disavowal denies the economy, transfiguration positively transforms it. Often through language and in the form of euphemism, the interested actor redefines what it is that is happening. "Transfiguration is essentially verbal," Bourdieu notes (1998:115). It involves telling others and oneself that "one is doing something other than what one is doing" (P. 115). In the case of direct selling, distributors transfigure the mundane sale of lipstick, leggings, and oils into a noble quest to lift women, heal families, and build community (Biggart 1989; Mullaney and Shope 2012).

"My platform," Anne tells me,

is to get women to love themselves no matter what. Like no matter if you think you're fat, if you think you're ugly. [...] You still have to love yourself. Like, it doesn't change your worth, you know. Your weight doesn't define your worth. So that's my platform.

Like others, Anne frames her work as driven fundamentally by a desire to encourage and empower other women. In a narrow sense, Anne's job is objectively about recruiting women to purchase and sell lipstick and other skin care products. But in her telling of it, direct selling is so much more.

Appealing to the generosity of their work was a common refrain in interviews, as distributors spoke-sometimes with great emotion-about how they were inspired and sustained by their interest in helping women love themselves and connect with a community of supportive women. Tracy's story is personal. Raised in an abusive home and suffering through six abusive marriages, her backstory sets the context for how she talks about selling Motif clothes and what she now sees as her reasons for doing so, which she characterizes in decidedly other-focused terms. "I'd been looking for a way to really get out and make a difference to these women who were feeling not very good about themselves," she explains. "And so for me, when I started, it really was kind of this, 'Oh my gosh, I found my direction. I found the way that I'm supposed to be going out and spreading this message,' you know? [...] I wanted to go out there and just show women how good they could feel. And $[\ldots]$ the clothes were just a tool."

Distributors like Tracy believe they empower women by helping them feel beautiful, by showing them ways to care for their bodies, by helping them earn extra income, and by building a community of supportive women. Emphasizing each of these ambitions draws attention to the needs of the potential buyer (not the seller) and transforms discursively the potentially disingenuous and instrumental calculations behind selling into something genuine and selfless. Erica articulates her disinterest in the economic aspect of her relationships by declaring magnanimously, "Like, that's not my purpose... to just make a lot of money, sell a lot of things, you know?" She shows disinterest not only through disavowal, however, but also 
through transfiguration. It's not just that she's not motivated by the financial aspect of selling; direct selling is a tool to care for other women: "It's because the clothes helped me feel better. Can I help you feel better?" Likewise, Melanie claims, "My [Facebook] page has turned into so much more than just my selling-my-clothes page," noting that her work gives her a "feeling of purpose" that even her job at an area hospital did not provide. "It's just a total community of amazing women that really make sure to go out of their way to lift each other up."

The economically disinterested focus on helping others takes on a unique hue when the product being sold is not apparel and makeup but the essential oils or dietary supplements that purveyors believe are useful for caring for the spirit and body. Essential oils distributors see themselves not as salespeople but as healers. "My thing was, I didn't want to leave this life not making a difference," Jessica explains.

So if I made a difference in one person's life, awesome, you know. [... ] I just want to make a difference, and so I always had ideas of what I could do to just make the world a little bit better when I'm gone, you know. So Essence was sort of that way. Like, I got to [...] make a difference [in] one person's life, you know, [even] if it was just getting them out of pain. Just like, "Oh that mattered," you know? Because now I have this person off of prescription medication, and now she can take care of her kids. I can't even tell you how many stories I have like that. [...] I get to go out there and fill my cup by helping other people.

Whether they are selling leggings or essential oils, distributors have a way of communicating their work that transfers the need for the sell away from themselves and towards others. By focusing attention on others' physical, emotional, and social needs, they suggest indirectly - and sometimes state directly-that they are in the business of helping others find joy and health, which in turn justifies their work.

Distributors' manner of speaking about their efforts in prosocial terms must be situated within the context of the organizations for which they work. Direct selling companies provide opportunities for disinterested action and encourage disinterested narratives that distributors then adopt and apply in their direct selling work. When Anne tells me in conversation that her mission is to strengthen and enable women, she is actually restating the company motto verbatim. And when Heidi declares that her goal is to help "people to-like women, specifically-to feel good about themselves," she is verbalizing a commitment solidified at a Glitz workshop in which participants contemplated "their why" - why they, the attendees, were personally selling lipstick and other skin care products. Laughing, Heidi recalls, "I was like, 'Well, my why is I wanna make money...'" The workshop facilitator, however, would not hear it. She encouraged Heidi to dig "real deep," to search for "what fulfills me." It was not until that moment that it occurred to Heidi that her true purpose was not to sell lipstick but, rather, to help women feel good and powerful. Indeed, such efforts to reflect on, clarify, and develop one's "why" is a significant part of multilevel marketing culture. 


\section{Disinterest through Displacement}

Notwithstanding his cursory treatment of disinterested actors and their actions, we can find in Bourdieu's writings at least two ways that agents manifest disinterestdisavowal and transfiguration. Above, I showed how these work in the direct selling industry. My data suggest two additional types of disinterest: displacement and transposition. Displacement occurs when actors offer a disinterested narrative intended to outcompete the interested one. When distributors talk about connecting with and caring for others, they are offering a rival account to the economic explanation of their actions. If they articulate it enough times, the alternative storyline, the prosocial one, might come to seem more accurate than the economic one.

Displacement has an affinity with transfiguration, but they are not the same. Transfiguring is meant to change the transaction into something nobler (Bourdieu 1998:99), whereas displacement is meant only to crowd it out. In transfiguration, the economic transaction (e.g., the donation to pay a mortgage, continuing the example from the Background section) becomes a sacred one (a tithe to further God's work). By contrast, in displacement, the economic transaction remains untransformed. Not all of my interviewees suggested that transacting lipstick for money, for instance, was in and of itself a meaningful endeavor-that is, the economic transaction was not necessarily euphemized. But even in such cases, distributors stress the value of the social aspects of their direct selling work. By emphasizing the social, they offer a complementary storyline-not a substitute, but a competitor-about why they are doing what they are doing. Yes, they are selling lipstick, and, yes, that is an interested economic transaction, but its importance pales in comparison with their disinterested pursuit of meaningful relationships. These relationships might be with customers or fellow sellers, either of which overshadows the economic aspect of their selling and recruiting behavior.

In interviews, distributors characterize their work in relationship-saturated terms. This talk at times has an instrumental quality, as distributors speak in ways that would be familiar to any savvy salesperson who knows how to take care of her client. But distributors do not necessarily draw sharp lines between treating others well because it helps increase sales and treating others well because they genuinely care about those with whom they are interacting. Moreover, they emphasize that their relationships matter even if they are not ultimately lucrative.

Distributors frame their business relationships as socially meaningful (not just remunerative) in several ways. One is by recasting business relations in familiarand sometimes familial-terms (see also Biggart 1989). For instance, Kelly, like Audrey, conceptualizes the people who purchase clothes from her as "friends, not customers." To provide evidence of their shared intimacy, she notes that she "knows about surgeries they've had, and issues with their parents and taking care of them, and kids' stuff." "They share a lot with me," she says, "so it does feel very much like a community." Women such as Nancy report that "my closest friends" are their direct selling associates. "We used to not have close friends," Amy tells me. "Now we have people that we would consider family. Like, that close. Even closer than family, in some ways." "The thing is," Elizabeth says, "it's a sisterhood. I know you might have heard that before, but it is a sisterhood. [...] There's a bond." 
Distributors say they prioritize these friendships as important as, or more important than, any financial gains they might receive from direct sales. They value friendships not just as a bonus of working in direct selling but, instead, as the primary benefit of their work. Jill, for example, situates a potential sell within the context of a relationship, rather than the other way around. "If I'm meeting with a friend," she says, "my sole purpose isn't just to sell them something; it's still to be their friend." Emma agrees: "Building that relationship with people is more important than me talking about my business. So my focus is always, you know, getting to know people, being friends." "We're interested really in just getting to know the person and being their friend," Rachel explains. "If [the product] comes up, cool. I have something fun to offer them." But, she emphasizes, "I want to have a real conversation with you and not just, 'Here's my transaction.' "

Direct selling networks also provide opportunities for fun. The "fun" of direct selling-an industry feature observed by other scholars (Mullaney and Shope 2012) - reinforces the sense that distributors are not only working but, in fact, joyfully participating in a meaningful community of fellow friends. Direct selling companies actively promote a culture of fun, famously rewarding successful sellers with incentive vacations and organizing conferences and retreats that aim not only to train but to delight. Lori, who goes to convention every July, reports that "they make it really fun." "My kids are always like, 'Mom, you're going on vacation without us?' And I'm like [laughing], 'No, actually, I'm going to work.' " Elizabeth agrees: "Oh, they're so fun! It's like a huge party."

Distributors then pass on the fun to potential buyers, with whom they do not just make appointments to pitch products to wary consumers but, rather, host parties to hang out with eager friends. Distributors gamify these experiences, holding drawings, facilitating contests, and offering participants prizes and giveaways. Stephanie and her husband put on a show for their buyers during their Facebook Live sessions. "Everyone's cracking up," she says. "Like, so many people watch us who don't buy. [...] They love watching our banter." Importantly, she reflects, "there is this closeness" among the participants as a consequence.

Having fun is helpful for distributors in commercialized relationships. It builds the community that they feel is so important to them personally and professionally. Critically, it enables them to continue their direct selling work but to do so in a way that feels more "organic" (Cheri) — that is, less obviously calculated to capitalize economically on one's friends and family. It does so by communicating that the direct seller has interests other than ensuring the success of the business and that the association is grounded in something besides the financial transaction. Focusing on fun, then, is a way to prioritize the relational aspect of direct selling.

In the end, it is the relationships that make direct selling work meaningful, Nancy is careful to point out. "Yes, the money was awesome. [Laughs] And the trips were awesome. And they were so fun. But it's the relationships. Honestly, it's one hundred percent the friendships that I was able to make." In this telling, Nancy is not attempting to transfigure her exchanges into sacred, beautiful things. However, she identifies relationships as the most important aspect of her direct selling work, which situates the economic aspect of her work as secondary. She 
displaces what to an outsider might seem like the obvious interpretation-that is, Nancy is using her friends for personal gain-with a more generous interpretation.

\section{Disinterest through Transposition}

Finally, distributors show disinterest through transposition-that is, transferring something to a different place or context (New Oxford American Dictionary, third ed.: s.v. "transpose"). In commercialized relationships, it is economic interest that gets transferred to another location. Specifically, the protagonist transfers the responsibility of commercializing the relationship to the person with whom they are interacting. Distributors thus become disinterested by creating interested others. Transferring the liability of interest to others means creating the conditions that will motivate potential buyers to express interest in a product, leaving the distributor free from adopting wholesale the role of the interested seller. When this strategy is successful, the buyer, not the seller, takes the first apparent step towards a transaction, which makes all the difference from the distributors' perspectives, as it allows them to assume disinterest without hypocrisy. If that ideal is unattainable, the distributor's secondary aim is to discern potential buyers' needs and wants, even if the potential buyer has not yet connected their fulfillment to the product for sale. As long as the distributor is addressing a stated or implied desire, she has not, in her mind, violated the code of disinterested selling.

To realize one of these two goals-that is, cultivating an expression of interest in the product or at least obtaining a revelation of the potential buyer's wants or needs-the distributor must make others aware of the product for sale without suggesting that she cares too much about selling. She does this by using two tactics, both of which take place through face-to-face and social media networks. In each, the governing principle is the same: don't pitch the product unless the potential buyer first shows interest. "I never pushed," Tracy says, verbalizing the mandate, which means, "I never talked to somebody that I didn't think had some interest in it."

The wait-and-see. In the more passive of the two approaches to cultivating an interested other, the direct seller wears or uses the product conspicuously, hoping that it will generate others' expressions of interest (similar to Mullaney and Shope 2012:41). One way that Kelly avoids becoming "that person" (i.e., that interested person) is by wearing Motif clothing and hoping that it will prompt a response by an envious observer. "I always wear a Motif to church, like head to toe, always," she says, "because I feel like I am my best form of walking advertisement." With luck, another congregant will express interest in Kelly's attire, which will open the door to a conversation that Kelly is happy to engage in but does not (and typically would not) initiate. Approaching the transaction in this way, Kelly facilitates the exchange with her disinterested, non-"salesy" identity intact.

Julie expresses the key to a wait-and-see approach: "I let them pursue it. I don't, like, you know, text them, like, 'I got new stuff. You got to come over.' " Doing so, after all, would position her as an interested seller. Instead, she says, "I let them initiate it," which is similar to Brittany's effort "to make it as voluntary as possible" and Jill's rule of thumb: "If they bring it up, that's totally fine. I'll talk 
to them about it, but it's not like I'm gonna bring it up first." By letting others initiate the exchange-by making it feel voluntary-distributors believe they protect themselves from being seen by others as aggressive, interested distributors.

Sometimes the wait-and-see fits seamlessly into a distributor's daily routine, and the distributor insists that wearing or using the product is "natural" (or, similarly, "organic" and "normal"), not contrived. At other times, however, distributors more actively construct wait-and-see moments in hopes of generating buyer interest. In an interview with Lori, I asked how a leader in Motif would help a new distributor overcome fears of selling to family members. Her answer was to invite some family members over and to "just have some Motif-like a rack [of it]" sitting out. Overt as that might be, it serves the purpose of generating an interested buyer who can own the responsibility of commercializing the relationship.

Passive engagement. Distributors will sometimes move past the wait-and-see by engaging directly, if still passively, with potential buyers. More direct than simply wearing, using, or displaying the product, but passive in that it relies ultimately on a potential buyer signaling interest in the exchange, some women initiate faceto-face (or online) conversations that they hope will "naturally" or "organically" turn towards their direct selling work. This second form of disinterested selling is notable in that the distributor maintains her resistance to pitching the product outright and yet more deliberately shapes the circumstances in which the product (or a need for it) might arise. It is still an "if you want something, come and get it type thing," as Jill explains, but the distributor does more to ensure that the potential buyer will, in fact, "come and get it."

Cheri explains that she "would use hints to get people to ask me questions." She trains other distributors to have an "elevator pitch" whose intent is to create an interested other: "I would say, 'You know, you have 15 seconds until they've moved on. And so you need 15 seconds where you get them asking you questions, so they don't feel like you're the one telling everything.' " For example, in a conversation, "I'd be like, 'Oh, my gosh. My whole family's going on a cruise next week.'" The interlocutor would likely respond, "Oh, you are? Where you going?," to which Cheri would suggest answering, "We're going to Jamaica. It's all free.'" "And then leave it," she tells me. No doubt the person to whom she is talking would then ask how she is doing it for free, and with the liability of interest thus effectively transferred, Cheri could engage in a conversation about Splendor without risking damage to her identity as a disinterested distributor. She is being indirect and unassertive; most importantly, she is enacting disinterest.

When potential buyers do not provide an explicit signal of interest, some distributors discern their needs based on face-to-face and online interactions, and they then connect their product to those needs. Because the interest originates implicitly with the potential buyer, this also does not violate the expectations of disinterested selling. So, when a potential buyer tells Kayla that she has a headache, then Kayla feels free to suggest a supplement that she sells through Vital. As with others, Kayla recognizes the value in taking a passive approach: "I feel like it's a lot more genuine coming from them, too, when I'm not shoving a business or product down their throat." 
As with the wait-and-see, most distributors do not see this approach as "pushy," and it therefore does not implicate them as interested. "I don't reach out to people," Grace insists, "They reach out to me." Thus, whether face-to-face or on social media, distributors like Elizabeth cultivate the interest in others so that "they'll come" to her. Sometimes it happens "naturally," as distributors go about their days wearing a favorite color of lipstick and acquaintances or friends signal their notice. Sometimes it is contrived. Either way, the strategies are similar in that the distributor relies primarily on the potential buyer to show interest, which frees the seller to discuss the product.

\section{Discussion and Conclusion}

How are relationships possible in commercialized settings, where everything is for sale, even those relationships? I examine this question by investigating one side of commercialized relationships and asking, specifically, how sellers align their economic interests with their relational ones. Commercialized relationships are problematic because they call into question the intrinsic orientation of an acquaintance, friend, or family member who is promoting an economic transaction that will result in their personal financial benefit (Grayson 2007). At stake is nothing less than the relationship itself.

How people make sense of and navigate their economic and social lives is a central problem in economic sociology (Bandelj 2020; Zelizer 2012), and the case of direct selling provides an opportunity to examine it in sharp relief. After all, distributors engage regularly in economic transactions with known-and sometimes intimate-others. They are not oblivious to the concerns presented by commercializing relationships, however, and they exert effort to balance their economic and social interests. The nature of the work that goes into managing commercialized relationships is the focus of this article, and I find that distributors display a style of interacting anticipated but not fully developed by Bourdieu. Its main feature is disinterest.

Calling it disinterest is not meant to suggest that the economic actors who show it are truly uninterested actors (Bourdieu and Wacquant 1992; Bourdieu 1998; Grenfell 2012; Swartz 2012; Swedberg 2005)—in that they do not care at all about the economic consequences of their relationships. Because we are here dealing with commercialized relationships, economic actors are necessarily interested in both the relational and financial aspects of their work. Although the degree of raw economic interest might vary from person to person, it is always present. To say that someone is disinterested, then, is not a statement about their deep level of care for things financial. It is a statement about their style - the way they approach their work and relationships, and the manner in which they understand and talk about them.

Displays of disinterest are also not necessarily disingenuous. They certainly could be, but it is just as possible that participants in a relationship believe-or want to believe- that they are not themselves economically motivated (see Bourdieu 1990:53). In subscribing to the notion that economic transactions corrupt, people have reason to frame their actions as lacking financial motivation, but they may do so unwittingly. Whatever the deep reasons for their apparent disinterest, it is 
probably less important than the fact that disinterest is easily identifiable when participants in a relationship manage their shared pecuniary concerns.

I highlight two specific contributions based on these findings. First, I bring Bourdieu into closer dialogue with economic sociologists who are intent on understanding the interplay of economic and social activity. Some of the research in this vein examines the moral underpinnings of economic activity (Biggart 1989; Livne 2014), including how evolving cultural meanings enable economic practices that were once taboo (Quinn 2009; Zelizer 1979) or provide opportunities for opposition to mainstream economic practices (Kiviat 2019). Other work contemplates how narrative, practices, bodies, and organizations (including their histories) all shape how people experience economic activities and respond to them (Almeling 2007; Anteby 2010; Reich 2014). Relational economic sociologists have been particularly interested in the efforts that people exert to reconcile their economic and social lives (Bandelj 2020). They recognize that good economic transactions involve more than having the right technology or media; they require relational work as well (Zelizer 2006). Zelizer (2005), for instance, has written at length about how economic activity serves to mark and differentiate relationships.

I build on the relational-focused research in economic sociology by offering a complementary account of how people work to make good matches in the face of commercializing pressures. Although many scholars have written about the work that goes into reconciling the economic and social qualities of relationships, and many have written also about Bourdieu's notion of disinterest, these two literatures have seldom been brought into contact with each other. When economic sociologists do use Bourdieu, it is often for different purposes: to make sense of elites (Hahl and Zuckerman 2014; Hahl et al. 2017), cultural production (Ardery 1997), distinction (Schor et al. 2016), and outsider perceptions (Schilke and Rossman 2018). By contrast, I present Bourdieu's notion of disinterest as a (partial) solution to the relational problem of commercialized relationships.

There is an obvious connection here to Schilke and Rossman's (2018) concern with obfuscation. Their primary focus, however, is on how the structure of an exchange obfuscates its problematic nature to outsiders. By contrast, my focus is on how a disinterested style might serve to obfuscate the problematic nature of an exchange to the participants themselves. Obfuscation is still at play, but it is not external audiences only who are subjected to it. Moreover, my research implicates the actors' actions, not just the structure of the exchange, as the genesis of obfuscation.

Second, I excavate Bourdieu's theory of disinterest, suggesting four distinct types. Two can be found in Bourdieu's writing, and two are types I offer based on my data. Like Goffman when he is musing on frames or the presentation of self, Bourdieu suggests the elements of a basic interactional form applicable to a variety of settings. Bourdieu's own work, and that of other scholars writing about disinterest, focuses primarily on the function of disinterest in fields such as religion (Bourdieu 1998), cultural production (Ardery 1997; Bourdieu 1980; Bourdieu 1983; Hahl et al. 2017), science (Merton 1942), and the like. Although disinterest is surely operative in such sites, those who operate it largely fade into the background (Schor 
Table 1: Types of disinterest.

\begin{tabular}{lllll}
\hline Disavowal & $\mathrm{E}$ & $\rightarrow$ & $\mathrm{E}$ & Claim that E does not exist \\
& $\mathrm{S}$ & $\rightarrow$ & $\mathrm{S}$ & \\
\hline \multirow{2}{*}{ Transfiguration } & $\mathrm{E}$ & $\rightarrow$ & $\mathrm{S}$ & Transform E into S \\
& $\mathrm{S}$ & $\rightarrow$ & $\mathrm{S}$ & \\
\hline \multirow{2}{*}{ Displacement } & $\mathrm{E}$ & $\rightarrow$ & $\mathrm{E}$ & \multirow{2}{*}{ Emphasize S to crowd out E } \\
& $\mathrm{S}$ & $\rightarrow$ & $\mathrm{S}$ & \\
\hline \multirow{2}{*}{ Transposition } & $\mathrm{E}$ & $\rightarrow$ & $\mathrm{E}^{\prime}$ & \multirow{2}{*}{ Transfer E to another person, keep S } \\
& $\mathrm{S}$ & $\rightarrow$ & $\mathrm{S}$ & \\
\hline
\end{tabular}

Note: Commercialized relationships have economic qualities (represented with the letter E) and social, or noneconomic, qualities (represented with the letter S) in the first column of Es and Ss. The second column of Es and Ss represents how disinterest aims to change them in relation to each other.

et al. 2016). We are therefore left with the sense that disinterest is important but without much guidance on what it looks like and how we might identify it.

Table 1 summarizes four ways of showing disinterest. Each form of disinterest is unique in how it deals with the central problem of commercialized relationships: that they by definition have both economic and social (noneconomic) qualities to them, characterized, respectively, by the letters $S$ and E. Not only must the protagonists of these relationships maintain the noneconomic aspects of their relationships (S), they also need to deal with the constant presence of economic interests (E). They do so by claiming that economic interest simply does not exist (disavowal) or by transforming economic interest into a noneconomic alternative (transfiguration). Much of the research in economic sociology—for example, sacralizing life insurance (Zelizer 1978) or providing for a dignified death through viaticals (Quinn 2009)—focuses on transfiguration.

Participants to commercialized relationships also emphasize their noneconomic (i.e., disinterested) commitments by taking steps to increase the likelihood that those interests will be seen as more important than the obvious economic interests that their selling behavior reveals (displacement). Table 1 represents this by increasing the size of $S$ and decreasing the size of $E$, suggesting that the former is crowding out or overshadowing the latter. Finally, by turning the tables on others, protagonists of commercialized relationships aim to transfer economic interest away from themselves and onto others (transposition). Table 1 represents the transfer as a shift from $\mathrm{E}$ to $\mathrm{E}^{\prime}$. If successful, transposition purifies a person's role in the relationship by sanitizing them of economic interest, which becomes the sole burden of others with whom the person is interacting.

As the forgoing analysis suggests, disinterest is not just a stance useful for creating inanimate products (a painting, a journal article); it is also a relational strategy useful for creating and maintaining living relationships (e.g., those with a mother, a friend). Moreover, disinterest does more than bolster claims of authenticity for outside observers (à la Bourdieu 1983); it also provides a way for a participant in a commercialized relationship to thread the needle of being interested in the 
economic benefits of a friendship while also maintaining her identity as a thoughtful, caring friend. With some good fortune, her disinterested approach might protect the relationship from suffering the negative relational consequences that obtain when one actor uses another for obvious instrumental gain.

There are two weakness to this study that future scholarship could address. First, I do not report here on how others experience distributors' show of disinterest, so this article assesses only one side of the relationships in question. How potential buyers understand direct selling addresses a useful but altogether different question than the one asked here. Here, I am interested in how the protagonists in these relationships-the sellers themselves-manage their economic interests in the context of their social commitments. Whether their disinterested approach "works" is a multifaceted question, and although this article cannot say whether it does so for potential buyers, being disinterested does apparently work for distributors. They use it to understand and frame their work, which provides useful—if still partial—insight into how people navigate and maintain commercialized relationships.

Second, the data reported here rely on distributors' own accounts, which could raise questions about their trustworthiness. Fortunately, this is not a major issue for these findings. The evidence reported here shows how distributors characterize their work. Although there are reasons to suspect that they were being candid in their assessments (e.g., I am an outsider to the industry, they provided accounts that sometimes cast them in a negative light, etc.), what is most important, for our purposes here, is not to understand what truly motivates their work-an insight to which even they might not be privy. Rather, it is to understand how they conceptualize their work, even in the face of possible criticism.

\section{Notes}

1 Although treating a friend or family member as a potential customer or recruit (i.e., prospect) can make for off-putting social encounters, much of the criticism leveled at multilevel marketing enterprises is that their multilevel nature makes them predatory and exploitative (Monroe 2017; Richards 2019; Silverstein, Lee, and Kosciulek 2019). Indeed, an income disclosure statement released by one of the companies I studied showed that 90 percent of entry-level distributors earned an average of $\$ 3$ per year in 2019 , far less than the cost of the required start kit.

\section{References}

Almeling, Rene. 2007. "Selling Genes, Selling Gender: Egg Agencies, Sperm Banks, and the Medical Market in Genetic Material." American Sociological Review 72(3):319-40. https://doi.org/10.1177/000312240707200301.

Anteby, Michel. 2010. "Markets, Morals, and Practices of Trade: Jurisdictional Disputes in the US Commerce in Cadavers." Administrative Science Quarterly 55(4):606-38. https : //doi.org/10.2189/asqu.2010.55.4.606.

Ardery, Julia S. 1997. “'Loser Wins': Outsider Art and the Salvaging of Disinterestedness." Poetics 24(5):329-46. https://doi.org/10.1016/S0304-422X(96)00015-0. 
Bandelj, Nina. 2020. "Relational Work in the Economy." Annual Review of Sociology 46:251-72. https://doi.org/10.1146/annurev-soc-121919-054719.

Belk, Russell W., Melanie Wallendorf, and John F. Sherry Jr. 1989. “The Sacred and the Profane in Consumer Behavior: Theodicy on the Odyssey." Journal of Consumer Research 16(1):1-38. https://doi.org/10.1086/209191.

Belk, Russell W., and Melanie Wallendorf. 1990. "The Sacred Meanings of Money." Journal of Economic Psychology 11(1):35-67. https : //doi .org/10.1016/0167-4870 (90)90046-C.

Biggart, Nicole Woolsey. 1989. Charismatic Capitalism: Direct Selling Organizations in America. Chicago, IL: University of Chicago Press. https://doi.org/10.7208/chicago/ 9780226227269.001 .0001$.

Bourdieu, Pierre. 1980. "The Production of Belief: Contribution to an Economy of Symbolic Goods." Media, Culture E Society 2(3):261-93. https://doi.org/10.1177/ 016344378000200305.

Bourdieu, Pierre. 1983. "The Field of Cultural Production, Or: The Economic World Reversed." Poetics 12(4-5):311-56. https : //doi .org/10.1016/0304-422X (83) 90012-8.

Bourdieu, Pierre. 1984. Distinction: A Social Critique of the Judgement of Taste. Cambridge, MA: Harvard University Press.

Bourdieu, Pierre. 1990. The Logic of Practice. Stanford, CA: Stanford University Press.

Bourdieu, Pierre, and Loïc Wacquant. 1992. An Invitation to Reflexive Sociology. Chicago, IL: University of Chicago Press.

Bourdieu, Pierre. 1998. Practical Reason: On the Theory of Action. Stanford, CA: Stanford University Press.

Corbin, Juliet, and Anselm Strauss. 2014. Basics of Qualitative Research. Thousand Oaks, CA: Sage.

Direct Selling Association. 2019. "Direct Selling in the United States: 2018 Industry Overview." Washington, DC: Direct Selling Association. Retrieved April 22, 2020, https : //www.dsa. org/statistics-insights.

Durkheim, Emile. 1915. The Elementary Forms of the Religious Life. London: George Allen \& Unwin. Retrieved November 9, 2020, https://www.gutenberg.org/files/41360/ 41360-h/41360-h.htm.

Federal Trade Commission. 2018. “Business Guidance Concerning Multi-level Marketing." Washington, DC: Federal Trade Commission. Retrieved April 22, 2020, https://www.ftc.gov/tips-advice/business-center/guidance/businessguidance-concerning-multi-level-marketing.

Grayson, Kent. 2007. "Friendship versus Business in Marketing Relationships." Journal of Marketing 71(4):121-39. https://doi .org/10.1509/jmkg.71.4.121.

Grazian, David. 2005. Blue Chicago: The Search for Authenticity in Urban Blues Clubs. Chicago, IL: University of Chicago Press.

Grenfell, Michael James. 2012. Pierre Bourdieu: Key Concepts. 2nd ed. Porthcawl, UK: Acumen.

Hahl, Oliver, and Ezra W. Zuckerman. 2014. "The Denigration of Heroes? How the Status Attainment Process Shapes Attributions of Considerateness and Authenticity." American Journal of Sociology 120(2):504-54. https : //doi .org/10.1086/678304.

Hahl, Oliver. 2016. “Turning Back the Clock in Baseball: The Increased Prominence of Extrinsic Rewards and Demand for Authenticity." Organization Science 27(4):929-53. https://doi.org/10.1287/orsc.2016.1072. 
Hahl, Oliver, Ezra W. Zuckerman, and Minjae Kim. 2017. "Why Elites Love Authentic Lowbrow Culture: Overcoming High-Status Denigration with Outsider Art." American Sociological Review 82(4):828-56. https://doi .org/10.1177/0003122417710642.

Healy, Kieran. 2006. Last Best Gifts: Altruism and the Market for Human Blood and Organs. Chicago, IL: University of Chicago Press. https://doi.org/10.7208/chicago/ 9780226322384.001 .0001$.

Johnson, Randal. 1993. “Editor's Introduction: Pierre Bourdieu on Art, Literature and Culture." Pp. 1-27 in The Field of Cultural Production: Essays on Art and Literature, by Pierre Bourdieu. New York, NY: Columbia University Press.

Kiviat, Barbara. 2019. "The Moral Limits of Predictive Practices: The Case of Credit-Based Insurance Scores." American Sociological Review 84(6):1134-58. https://doi.org/10. $1177 / 0003122419884917$

Kuttner, Robert. 1999. Everything for Sale: The Virtues and Limits of Markets. Chicago, IL: University of Chicago Press.

Livne, Roi. 2014. "Economies of Dying: The Moralization of Economic Scarcity in US Hospice Care." American Sociological Review 79(5):888-911. https://doi .org/10 .1177/ 0003122414547756.

Lukes, Steven. 1985. Emile Durkheim, His Life and Work: A Historical and Critical Study. Stanford, CA: Stanford University Press.

Merton, Robert K. 1942. "A Note on Science and Democracy." Journal of Legal \& Political Sociology 1(1-2):115-26.

Miles, Matthew B., and A. Michael Huberman. 1994. Qualitative Data Analysis: An Expanded Sourcebook. Thousand Oaks, CA: Sage Publications.

Monroe, Rachel. 2017. "How Essential Oils Became the Cure for Our Age of Anxiety: Aromatic Oils Have Become Big Business. But Are They Medicine or Marketing?" New Yorker, October 9. Retrieved November 9, 2020, https : //www . newyorker . com/magazine/ 2017/10/09/how-essential-oils-became-the-cure-for-our-age-of-anxiety.

Mullaney, Jamie L., and Janet Hinson Shope. 2012. Paid to Party: Working Time and Emotion in Direct Home Sales. New Brunswick, NJ: Rutgers University Press.

Quinn, Sarah. 2009. "The Transformation of Morals in Markets: Death, Benefits, and the Exchange of Life Insurance Policies." American Journal of Sociology 114(3):738-80. https://doi.org/10.1086/592861.

Reich, Adam D. 2014. "Contradictions in the Commodification of Hospital Care." American Journal of Sociology 119(6):1576-628. https : //doi .org/10.1086/676836.

Richards, Laura. 2019. "How MLMs - Multilevel Marketing Schemes - Are Hurting Female Friendships." Chicago Tribune, January 22. Retrieved November 9, 2020, https://www . chicagotribune.com/business/ct-biz-mlm-female-friendshipcosts-20190122-story.html.

Sandel, Michael J. 2012. What Money Can't Buy: The Moral Limits of Markets. New York, NY: Macmillan.

Sayer, Andrew. 1999. "Bourdieu, Smith and Disinterested Judgement." Sociological Review 47(3):403-31. https://doi .org/10.1111/1467-954X.00179.

Schechner, Sam, Emily Glazer, and Patience Haggin. 2019. "Political Campaigns Know Where You've Been. They're Tracking Your Phone." Wall Street Journal, October 10. Retrieved November 9, 2020, https://www.wsj.com/articles/political-campaignstrack-cellphones-to-identify-and-target-individual-voters-11570718889. 
Schilke, Oliver, and Gabriel Rossman. 2018. "It's Only Wrong If It's Transactional: Moral Perceptions of Obfuscated Exchange." American Sociological Review 83(6):1079-107. https : //doi.org/10.1177/0003122418806284.

Schor, Juliet B., Connor Fitzmaurice, Lindsey B. Carfagna, Will Attwood-Charles, and Emilie Dubois Poteat. 2016. "Paradoxes of Openness and Distinction in the Sharing Economy." Poetics 54:66-81. https://doi.org/10.1016/j.poetic.2015.11.001.

Silver, Allan. 1989. "Friendship and Trust as Moral Ideals: An Historical Approach." European Journal of Sociology 30(2):274-97. https : //doi .org/10.1017/S0003975600005890.

Silver, Allan. 1990. "Friendship in Commercial Society: Eighteenth-Century Social Theory and Modern Sociology." American Journal of Sociology 95(6):1474-504. https : //doi .org/ $10.1086 / 229461$.

Silverstein, Sara, Jennifer Lee, and Amelia Kosciulek. 2019. "People Who Sell for Multilevel Marketing Companies Look Wildly Successful on Facebook, but the Reality Is Much More Complicated." Business Insider, August 6. Retrieved November 9, 2020, https: //www. businessinsider.com/mlms-use-social-media-facebookportray-financial-success-2019-7.

Sullivan, Bob. 2018. "Identity Theft Is Skyrocketing, and Getting More Sophisticated." MarketWatch, February 27. Retrieved November 9, 2020, https://www . marketwatch.com/story/identity-theft-is-skyrocketing-andgetting-more-sophisticated-2018-02-27.

Swartz, David. 2012. Culture and Power: The Sociology of Pierre Bourdieu. Chicago, IL: University of Chicago Press.

Swedberg, Richard. 2005. "Can There Be a Sociological Concept of Interest?" Theory and Society 34(4):359-90. https ://doi . org/10.1007/s11186-005-1986-3.

Weiss, Robert S. 1994. Learning from Strangers: The Art and Method of Qualitative Interview Studies. New York, NY: Free Press.

Zelizer, Viviana A. 1978. "Human Values and the Market: The Case of Life Insurance and Death in 19th-Century America." American Journal of Sociology 84(3):591-610. https : //doi.org/10.1086/226828.

Zelizer, Viviana A. 1979. Morals and Markets: The Development of Life Insurance in the United States. New York, NY: Columbia University Press. https://doi .org/10.7312/ zeli92046.

Zelizer, Viviana A. 1989. "The Social Meaning of Money: 'Special Monies.' " American Journal of Sociology 95(2):342-77. https ://doi . org/10.1086/229272.

Zelizer, Viviana A. 1996. "Payments and Social Ties." Sociological Forum 11(3):481-95. https : //doi .org/10.1007/BF02408389.

Zelizer, Viviana A. 2000. "The Purchase of Intimacy." Law E Social Inquiry 25(3):817-48. https://doi.org/10.1111/j.1747-4469.2000.tb00162.x.

Zelizer, Viviana A. 2005. The Purchase of Intimacy. Princeton, NJ: Princeton University Press.

Zelizer, Viviana A. 2006. “Money, Power, and Sex." Yale Journal of Law and Feminism 18:302-15.

Zelizer, Viviana A. 2012. "How I Became a Relational Economic Sociologist and What Does That Mean?" Politics E Society 40(2):145-74. https://doi.org/10.1177/ 0032329212441591. 
Acknowledgments: Many thanks to Sage Christianson, Eric Dahlin, Krista Frederico, Ben Gibbs, Jon Jarvis, Stacey Johnson, Jane Lopez, Heather Shurtliff, and Greg Wurm for support and comments on earlier drafts.

Curtis Child: Department of Sociology, Brigham Young University. E-mail: cchild@byu.edu. 